\title{
A study of drug utilization pattern in post-acute coronary syndrome (ACS) patients at tertiary care teaching hospital: a prospective unicentric study
}

\author{
Vidhi Thaker $^{1 *}$, Kamlesh Patel $^{2}$
}

${ }^{1}$ Department of Pharmacology, GCS Medical College, Hospital and Research Centre,

Ahmedabad, Gujarat, India

${ }^{2}$ Department of Pharmacology,

NHL Municipal Medical

College, Ahmedabad, Gujarat, India

Received: 06 November 2016

Revised: 19 December 2016

Accepted: 24 December 2016

*Correspondence to:

Vidhi Thaker,

Email: vidhi71284@yahoo.co.in

Copyright: (C) the author(s), publisher and licensee Medip Academy. This is an openaccess article distributed under the terms of the Creative Commons Attribution NonCommercial License, which permits unrestricted noncommercial use, distribution, and reproduction in any medium, provided the original work is properly cited.

\begin{abstract}
Background: The main objective of drug utilization research is to assess the rationality of drug use for specific disease. Long term survival in post-ACS patients depends largely on how well post ACS period is managed. Our aim is to record drug utilization pattern in post ACS patients after discharge and during follow-up visits.
\end{abstract}

Methods: Prospective unicentric study was conducted in 200 patients suffering from ACS at Cardiology OPD of GCS Medical College, Hospital and Research Centre, Ahmedabad. Prescriptions issued to study subjects at the time of discharge and during follow-up who had recently suffered from ACS were intercepted after consultation and data recorded as per WHO guidelines as how to investigate drug use. Data were collected in the structured proforma (Case Record Form-CRF) which includes patient's demographic details, registration number, diagnosis and the drug prescribed. Each prescription was analyzed using WHO core prescribing indicators to evaluate the rationality of the prescriptions.

Results: Out of 200, $104(52 \%)$ suffered from unstable angina, 84(42\%) suffered from STEMI and 12(6\%) were suffered with NSTEMI. Male patients of $114(57 \%)$ were more prone to ACS than female patients of $86(43 \%)$. Out of 200 patients, $193(97 \%)$ received antiplatelet, $187 \quad(94 \%)$ received antihypertensive, $184(92 \%)$ received anticoagulants, $180(90 \%)$ received lipid lowering drugs and $119(60 \%)$ received Nitrates. As per WHO core prescribing indicators, the average number of drugs encountered per prescription was 7.96. The prescription showed a high usage of drugs from NLEM i.e. $72.20 \%$ in postACS patients. However the percentage of drugs prescribed by generic name was only $10.68 \%$. The frequency of use of injectable preparations in post-ACS patients was found to be $17.84 \%$ which was in accordance with WHO reference value. Out of $17.84 \%$ injectable preparations, only $0.82 \%$ accounted for antibiotic injection.

Conclusions: Although generic prescribing indicator shows a low range of usage, it is interesting to notice that prescription pattern has a high usage of drugs from NLEM (78.2\%) in ACS. Thus present study provides valuable insight about the overall pattern of drugs used in post-Acute Coronary syndrome.

Keywords: Acute coronary syndrome, Drug utilization, Drug use pattern, NSTEMI, NLEM, STEMI

\section{INTRODUCTION}

Cardiovascular diseases (CVDs) are the main cause of mortality globally and are the leading cause of death in India also. Several surveys conducted across the country over the past few decades have shown a rising prevalence of major risk factors for CVD in Asian population. The problem of increasing risk factors for CVD in India is because of lack of surveillance system, proper diagnosis and appropriate treatment. ${ }^{1}$ 
The term acute coronary syndrome (ACS) refers to any group of clinical symptoms compatible with acute myocardial ischemia and covers the spectrum of clinical conditions ranging from unstable angina (UA) to non STsegment elevation myocardial infarction (NSTEMI) to ST-segment elevation myocardial infarction (STEMI). STEMI occurs by developing a complete occlusion of a major coronary artery previously affected by atherosclerosis. Unstable angina and NSTEMI are closely related conditions as their pathophysiologic origins and clinical presentations are similar, but they differ in severity. It is almost associated with rupture of an atherosclerotic plaque and partial or complete thrombosis of the infarct artery. A diagnosis of NSTEMI can be made when the ischemia causes severe myocardial damage that result in the release of a biomarker of myocardial necrosis into the circulation (cardiac-specific troponins $\mathrm{T}$ or $\mathrm{I}$, or muscle and brain fraction of creatine kinase [CK-MB]). While in UA no such biomarker can be detected in the bloodstream hours after the initial onset of ischemic chest pain. ${ }^{2}$ Patients with suspected acute coronary syndrome should be assessed immediately by an appropriate healthcare professional.

\section{Pharmacotherapy of ACS}

Standard guidelines recommend a door-to-balloon timetime from first medical contact to primary percutaneous coronary intervention (PCI) - of less than 90 minutes (according to the ACCF/AHA) or 60 minutes (according to the ESC) for patients presenting with STEMI. Significant reductions in mortality were noted between 1995 and 2015, largely attributed to reductions in time from symptom onset to first medical contact, greater use of reperfusion therapy, continuous multilead ST-segment monitoring, frequent measurement of vital signs and guideline recommended pharmacotherapy. ${ }^{3}$ The goal of pharmacological anti-ischemic therapy is to decrease myocardial oxygen demand (secondary to a decrease in heart rate, blood pressure, preload or myocardial contractility) or to increase myocardial oxygen supply (by administration of oxygen or through coronary vasodilatation). If, following treatment, the patient does not rapidly become free of ischemic signs or symptoms, immediate coronary angiography is recommended independently of ECG findings and cardiac troponin levels. In patients whose ischemic symptoms are not relieved by nitrates and beta-blockers, opiate administration is reasonable while waiting for immediate coronary angiography, with the caveat that morphine may slow intestinal absorption of oral platelet inhibitors. ${ }^{4}$

The efficacy of pharmacological therapy at symptom onset, throughout hospitalization, and at discharge is the important criteria for treatment of ACS. ${ }^{4}$ Various medications that impact the function of coronary disease include nitrates (intravenous, oral, and topical), beta blockers, calcium channel blockers, ranolazine therapy, warfarin/new anticoagulants, angiotensin-converting enzyme inhibitors, angiotensin receptor blockers, aldosterone, diuretics, statins, and other lipid-lowering medications, nonsteroidal anti-inflammatory drugs, insulin, oral hypoglycemics, influenza, and pneumococcal immunizations. ${ }^{5}$

Primary objective of this study is to known the drug utilization pattern in acute coronary syndrome patients. ${ }^{6}$ Drug utilization services practically appreciated in different clinical setting, health care management programs, hospitals and communities by considering therapeutic drug class and disease condition to assess the fundamental part of patient care system. ${ }^{7}$ The World Health Organization (WHO) regarded drug utilization as promotion, distribution, prescribing pattern and use of drugs within health care organization with main emphasis on therapeutics, societal and financial consequences. ${ }^{8}$

\section{METHODS}

This is a prospective unicentric study conducted in 200 patients suffering from Acute Coronary Syndrome (ACS) at Cardiology OPD of GCS Medical College, Hospital and Research Centre, Ahmedabad. The study protocol was approved by the Institutional Review Board Committee. Prescriptions issued to study subjects at the time of discharge and during follow-up who had recently suffered from ACS ( unstable angina, ST elevation and non-ST elevation acute myocardial infarction diagnosed by biochemical test or ECG) were intercepted immediately after consultation and data recorded as per WHO guidelines as how to investigate drug use. Data were collected in the structured proforma (Case record form- CRF) which includes patient's demographic details, registration number, diagnosis and the drug prescribed. Each prescription was critically analyzed using WHO prescribing indicators to evaluate the rationality of the prescriptions.

\section{Assessing prescribing indicators include}

A. Names, dose, dosage regimen, duration of all drug prescribed.

B. Average number of drug per prescription (encounter)

C. $\%$ of drug prescribed by generic name.

D. $\%$ of encounters resulting in prescriptions of an antibiotic

E. \% of encounters resulting in prescriptions of an injection

F. $\%$ of drugs prescribed from National List of Essential (NLEM).

\section{Assessment parameters}

Patterns of different drug use (antiplatelets, Beta blockers, ACEIs /ARBs, Statins, anticoagulants etc.).

A statistical analysis was done by using the SPSS software-version 21 and Microsoft excel. 


\section{RESULTS}

Out of 200, male patients of $114(57 \%)$ were more prone to ACS than female patients of $86(43 \%)$ (Table 1).

Table 1: Gender distribution of ACS.

\begin{tabular}{|lll|}
\hline Gender & Number & Percentage (\%) \\
\hline Male & 114 & 57 \\
\hline Female & 86 & 43 \\
\hline
\end{tabular}

$104(52 \%)$ suffered from unstable angina, 84 (42\%) suffered from STEMI and $12(6 \%)$ suffered from NSTEMI (Figure 1).

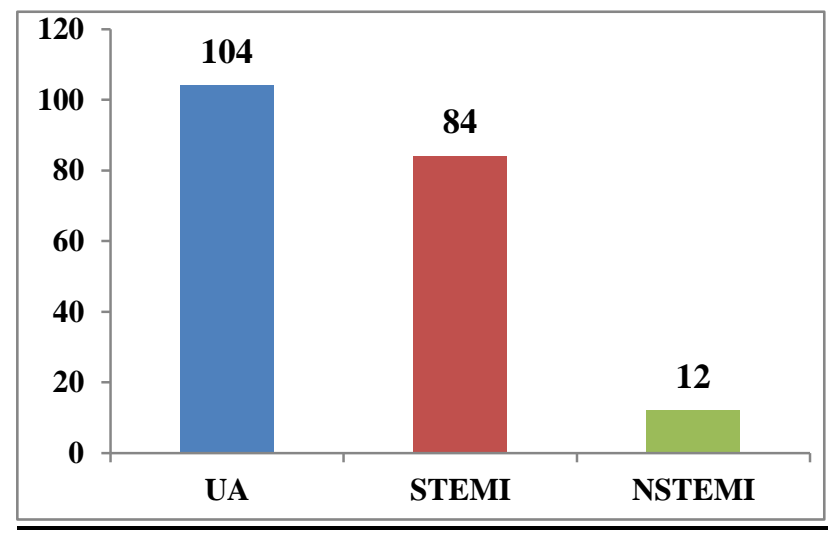

Figure 1: Incidence for different types of ACS.

\section{Age wise categorization of the patients}

Cardiac disorders progresses with the advancing age. When categorized age-wise, maximum number of patient $(25.5 \%)$ were from the age group of 51-60 years, followed by $24 \%$ from the age group of $61-70$ years. There was significantly lower number of patients in the younger age i.e. $2.5 \%$ in the age group of 21-30 years and $2 \%$ in the elderly age group of 81-90 years (Table 2 ).

Table 2: Age wise distribution for incidence of ACS in study population.

\begin{tabular}{|lll|}
\hline Age group & Incidence & Percentage (\%) \\
\hline $21-30$ & 5 & 2.5 \\
\hline $31-40$ & 19 & 9.5 \\
\hline $41-50$ & 40 & 20 \\
\hline $51-60$ & 51 & 25.5 \\
\hline $61-70$ & 48 & 24 \\
\hline $71-80$ & 32 & 16 \\
\hline $81-90$ & 4 & 2 \\
\hline $91-100$ & 1 & 0.5 \\
\hline
\end{tabular}

\section{Drug use pattern in ACS}

Branded prescribing dominated by $89 \%$ i.e. 1422 among 1592 drugs prescribed and only $10.68 \%$ i.e. 170 among 1592 drugs were prescribed by generic name (Table 3 ).
Table 3: Drug use pattern in ACS.

\begin{tabular}{|lll|}
\hline Type of Drug & Frequency & Percentage \\
\hline Branded Drugs & 1422 & 89.32 \\
\hline Antibiotics & 13 & 0.82 \\
\hline Injectables & 284 & 17.84 \\
\hline NLEM & 1245 & 78.20 \\
\hline Generic Drugs & 170 & 10.68 \\
\hline
\end{tabular}

The number of encounters with antibiotics was 13 $(0.82 \%)$. Injectable drugs accounted for $284(17.84 \%)$ of total encounters. The average number of drugs prescribed per encounter was in between 6-8. The percentage of drugs prescribed from national EDL was 1245 drugs i.e. $78.20 \%$.

Table 4: Results of drug use patterns in ACS with WHO prescribing indicators.

\begin{tabular}{|lll|}
\hline $\begin{array}{l}\text { Prescribing Indicators } \\
\text { assessed }\end{array}$ & $\begin{array}{l}\text { Standard } \\
\text { derived or } \\
\text { ideal }^{\text {P }}\end{array}$ & Percentage \\
\hline $\begin{array}{l}\text { Average number of drugs } \\
\text { per encounter }\end{array}$ & $1.6-1.8$ & 7.96 \\
\hline $\begin{array}{l}\text { Percentage of encounters } \\
\text { with an injection } \\
\text { prescribed }\end{array}$ & $13.4-24.1$ & 17.84 \\
\hline $\begin{array}{l}\text { Percentage of encounters } \\
\text { with an antibiotic } \\
\text { prescribed }\end{array}$ & $20.0-26.8$ & 0.82 \\
\hline $\begin{array}{l}\text { percentage of drugs } \\
\text { prescribed in generic } \\
\text { name }\end{array}$ & 100 & 10.68 \\
\hline NLEM & 100 & 78.2 \\
\hline
\end{tabular}

\section{Category wise prevalence of major drug classes in ACS}

All patients received different classes of cardiac drugs. Out of 200 pateints, $193(97 \%)$ received antiplatelets, 187 (94\%) received antihypertensives, $184(92 \%)$ received anticoagulants, $180(90 \%)$ received lipid lowering drugs and $119(60 \%)$ received Nitrates (Table 5).

Table 5: Category wise prevalence of various drug classes in ACS.

\begin{tabular}{|lll|}
\hline $\begin{array}{l}\text { Most commonly } \\
\text { prescribed group of drugs }\end{array}$ & $\begin{array}{l}\text { No. of patients } \\
\text { received out of } \mathbf{2 0 0}\end{array}$ & $\boldsymbol{\%}$ \\
\hline Antiplatelets & 193 & 97 \\
\hline Antihypertensive & 187 & 94 \\
\hline Anticoagulants & 184 & 92 \\
\hline Lipid Lowering Drugs & 180 & 90 \\
\hline Nitrates & 119 & 60 \\
\hline
\end{tabular}

\section{DISCUSSION}

In our study we analyzed 200 patients of ACS during the period of two years. Out of 200, male patients were more 
prone to ACS than female patients while prevalence of unstable angina was more compared to STEMI and NSTEMI. When categorized age-wise, maximum number of patient was from the age group of 51-60 years and significantly lower numbers of patients were from the elderly age group of $81-90$ years. Branded prescribing dominated over generic name.

The average number of drugs per encounter was found between 6 to 8 in our study which are deviated from the standard prescribed. The frequency of polypharmacy was higher in this hospital setting. One possible explanation is that, in tertiary care, patients seek expert advice from a health professional for very specific complaints, resulting in increased number of drugs per prescription. ${ }^{9}$ High prescription rates increases the risk of adverse drug reactions and drug interactions which affects the patient's quality of care. Frequency of use of antibiotic preparations was found to be very low $(0.82 \%)$ in ACS in comparison with WHO reference value. In present study we can observe that generic prescribing indicator shows a low range of usage at $10.68 \%$, resulting in a chance for errors and polypharmacy. Generic prescribing is beneficial as it reduces the cost of drugs. However, it is interesting to notice that prescription pattern has a high usage of drugs from NLEM (78.2\%) in ACS (Table 4).

The present study provides valuable insight about the overall pattern of drugs used in post-acute coronary syndrome. Extensive patient education, early assessment and aggressive treatment by multidisciplinary team represent the best approach to the management of high risk patients with cardiovascular disease. Clinical and economic outcomes demonstrate the reduction of cardiac complications, length of hospital stay and cost. ${ }^{10}$ Physicians should be motivated to prescribe drugs with generic name so as to reduce the cost of therapy. The primary purpose of NLEM is to promote rational use of medicines considering efficacy, safety and cost.

Funding: No funding sources Conflict of interest: None declared

Ethical approval: The study was approved by the Institutional Ethics Committee

\section{REFERENCES}

1. Nag T, Ghosh A. Cardiovascular disease risk factors in Asian Indian population: A systematic review. J Cardiovasc Dis Res. 2013;4(4): 222-8.
2. Kumar A, Christopher P. Cannon. Acute Coronary Syndromes: Diagnosis and Management, Part I. Mayo Clin Proc. 2009;84(10):917-38.

3. Puymirat E, Simon T, Steg PG. Association of changes in clinical characteristics and management with improvement in survival among patients with ST-elevation myocardial infarction. JAMA. 2012;308(10):998-100.

4. Roffi M, Patrono C, Jean-Philippe C, Christian M. 2015 ESC guidelines for the management of acute coronary syndromes in patients presenting without persistent ST-segment elevation. European Heart Journal. 2015:1-59.

5. Cannon CP, Brindis RG, Chaitman BR, Cohen DJ. 2013 ACCF/AHA Key Data Elements and Definitions for Measuring the Clinical Management and Outcomes of Patients with Acute Coronary Syndromes and Coronary Artery Disease. Circulation. 2013;127:1052-89.

6. Ghosh A, Das AK, Pramanik S, Saha UK. Drug utilization study in patients of acute coronary syndrome on follow-up visits at a tertiary care center in Kolkata. Asian Journal of Pharmacy and Life Science. 2012;2(2):155-65.

7. Fahimi F, Baniasadi S, Behzadnia N, Varahram F Tabatabaie LG. Enoxaparin Utilization Evaluation: An Observational Prospective Study in Medical Inpatients.Iranian Journal of Pharmaceutical Research. 2008;7(1):77-82.

8. Kaur S, Rajagopalan S, Kaur N, Shafiq N, Bhalla A, Pandhi P, et al. Drug utilization study in medical emergency unit of a tertiary care hospital in North India. Hindawi Publishing Corporation, Emergency Medicine International. 2014:1-5.

9. Sri Chandana M, Achutha Lakshmi P, Satish K. An evaluation of drug use pattern in acute coronary syndrome patients using WHO prescribing indicators. World J of Pharmaceutical Res. 2015;4(2):2095-103.

10. Chandana N, Subhash V, Vijay G. A Prospective study on drug utilization of cardiac unit in acute myocardial infarction of hospitalized patients. Int $\mathbf{J}$ Pahramcotherapy. 2013;3(1):6-11.

Cite this article as: Thaker V, Patel K. A study of drug utilization pattern in post-acute coronary syndrome (ACS) patients at tertiary care teaching hospital: a prospective unicentric study. Int J Basic Clin Pharmacol 2017;6:308-11. 